\title{
Sistem Informasi Jasa Travel (SIJAVEL) Menggunakan Metode Waterfall pada Remember Travel
}

\author{
Duwi Cahya Putri Buani ${ }^{1}$, Indah Suryani ${ }^{2}$ \\ ${ }^{1}$ Teknik Informatika, Sekolah Tinggi Manajemen Informatika dan Komputer Nusa Mandiri \\ Email:duwi.dcp@nusamandiri.ac.id
}

\begin{abstract}
The development of Information Technology is currently very fast, so that all sectors of the economy need an information system, so that services run effectively and efficiently. In this study, the authors created a travel services information system (SIJAVEL) where this system records all tour package booking transactions. The design of SIJAVEL uses the Waterfall method, the waterfall method is a method that is very easy to follow by system designers, the waterfall method also has clear stages from the analysis stage, design to implementation, so that the system design document is well documented, from this research it can be concluded that SIJAVEL is able to overcome the problems that occur in Remember Travel, one of the problems is that it is less effective and efficient in service, using SIJAVEL services will be more effective and efficient, besides that it is also regarding administration which previously still used conventional systems and many documents were lost, with the existence of SIJAVEL administration becomes more orderly and documents are stored properly.
\end{abstract}

Keyword: Travel Services, Information Systems, Waterfall

\begin{abstract}
Perkembangan Teknologi Informasi saat ini sangat pesat sehingga semua sektor perekonomian membutuhkan sebuah sistem informasi, agar pelayanan berjalan efektif dan efesien. Dalam penelitian ini penulis membuat sebuah sistem informasu jasa travel (SIJAVEL) dimana sistem ini mencatat semua transaksi pemesanan paket wisata. Perancangan SIJAVEL menggunakan metode Waterfall, metode waterfall merupakan metode yang sangat mudah untuk di ikuti langkahnya oleh perancang sistem, metode waterfall juga memiliki tahapan yang jelas dari tahap analisa, disain sampai dengan implementasi, sehingga dokumen perancangan sistem terdokumentasi dengan baik, dari penelitian ini dapat disimpulkan bahwa SIJAVEL mampu mengatasi permasalahan yang terjadi di Remember Travel salah satu permasalahannya adalah kurang efektif dan efesien dalam pelayanan, dengan menggunakan SIJAVEL pelayanan akan lebih efektif dan efesien, selain itu juga mengenai administrasi yang sebelumnya masih menggunakan sistem yang konvensioanl dan banyak dokumen yang hilang, dengan adanya SIJAVEL administrasi menjadi lebih tertib dan dokumen tersimpan dengan baik.
\end{abstract}

Kata Kunci : Jasa Travel, Sistem Informasi, Waterfall 


\section{Introduction}

Remember Travel merupakan usaha kecil yang didirikan pada tahun 2012, Remember Travel memiliki pelanggan yang cukup banyak tetapi sistem pelayanannya masih konvensional, sehingga pelayanan kurang efektif dan efesien (Ridlowi \& Himam, 2018), serta sering terjadi kehilangan dokumen dan pencatatan data yang tidak tertib (Jayanti \& Iriani, 2014), sehingga remember travel membutuhkan sistem informasi yang dapat menyelesaikan permasalahn tersebut (Kamil \& Duhani, 2016). Komputer juga mempunyai kemampuan dalam menunjang tiga sistem, yaitu sistem pengolahan data elektronik, sistem penunjang keputusan dan sistem penunjang ahli (Rusmayanti, 2015). Penelitian sebelumnya yang dilakukan oleh (Abdulghani et al., 2017) dan (Maulana \& Rispiandi, 2015) fokus dari penelitian tersebut adalah promosi jasa travel, sedangkan SIJAVEL dirancang untuk menyelesaikan permasalahan administrasi pada Remember Travel, seperti pencatatan transkasi yang kurang efektif dan efesien serta sering terjadi kehilangan dokumen transaksi, dengan adanya SIJAVEL diharapkan dapat melayani pelanggan dengan lebih baik serta tidak ada dokumen yang hilang lagi karena tersimpan didalam sistem sebagai backup data dan dari data tersebut dapat di jadikan penunjang untuk pengambilan keputusan oleh pemilik Remember travel. Dengan adanya Teknologi Informasi yang di terapkan pada remember travel maka informasi akan didapatkan lebih cepat (Riskiono, 2018).

\section{Materials and Methods}

Metode yang digunakan dalam penelitian ini adalah metode pengumpulan data dan metode pengembangan perangkat lunak.

\subsection{Metode Pengumpulan Data}

Metode pengumpulan data yang digunakan adalah yang menunjukan kepada tujuan sasaran studi. Untuk lebih jelasnya akan di uraikan di bawah ini:

\section{1) Observasi}

Penulis mengumpulkan data dengan cara mengamati secara langsung terhadap permasalahan maupun alur kerja sehingga didapat data yang otentik dan informasi yang jelas. Hal itu dilakukan oleh penulis dengan tujuan agar data yang diperoleh akurat dan maksimal.

2) Studi Pustaka

Penulis mengumpulkan data dengan cara mengumpulkan literatur, jurnal, paper, dan bacaan-bacaan yang akan dibahas dengan bersumber pada buku-buku yang ada kaitannya dengan judul penelitian untuk membantu menyelesaikan pembangunan dalam sistem ini.

\subsection{Metode Pengembangan Perangkat Lunak \\ Metode yang digunakan pada} pengembangan lunak ini menggunakan model waterfall (Pressman, 2015), tahapan penggunaan metode watterfall adalah sebagai berikut:

1) Planning (Estimating, Scheduling, Tracking)

Pada tahap ini penulis akan membuat sebuah program aplikasi pemesanan paket wisata dan memiliki beberapa proses sebagai berikut, yaitu :

a. Proses pemesanan paket wisata

b. Proses input data konsumen

c. Proses transaksi pembayaran

d. Proses keterangan laporan transaksi

2) Modeling (Analysis \& Design)

Pada tahap ini penulis melakukan perancangan database dengan menggunakan Data Model, dan perancangan aplikasi menggunakan UML.

3) Construction (Code \& test)

Pada tahap ini akan mengubah dari bentuk desain menjadi bentuk program dan setelah pengkodean selesai, dilakukan pengujian sistem dan kode yang telah dibuat dengan bertujuan menemukan kesalahan yang mungkin terjadi. 


\section{Results and Discussion}

Hasil dari penelitian ini adalah sebuah aplikasi yang dapat digunakan untuk mencatat transaksi yang terjadi pada Remember Travel, dari proses pendaftaran sampai dengan proses pembelian paket wisata.

\subsection{Planning (Estimating, Scheduling,}

Tracking).

Tahapan ini menjelaskan mengenai rencana awal pembangunan sistem Jasa Travel dengan melakukan analisa kebutuhan sistem jasa travel yang dilakukan pada saat observasi lapangan. Analisa kebutuhan sistem sebagai berikut:

1) Sekenario Kebutuhan Pemilik Jasa Travel
a) Mengelola data Paket Wisata
b) Mengelola data Admin
c) Mengelola data Booking Paket Wisata
d) Mengelola Data Transaksi Pembayaran
e) Mengelola Laporan

2) Sekenario Kebutuhan Administrasi
a) Mengelola data Booking Paket Wisata
b) Mengelola Data Transkasi

\subsection{Modeling (Analysis \& Design)}

Tahapan berikutnya dalam penggunaan metode waterfall adalah Modeling, pada tahapan ini penulis menggunakan Data Model untuk mendisain database dan menggunakan UML untuk mendisain sistem.

1) Use Case Diagram

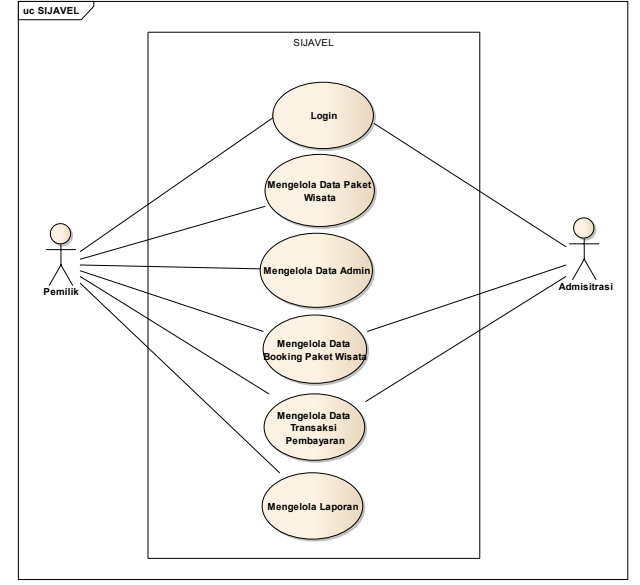

Sumber: (Buani \& Suryani, 2020)

\section{Gambar 1. Use Case Diagram SIJAVEL}

Gambar 3.1 menggambarkan lingkungan sistem dari SIJAVEL, dari use case diagram dapat dilihat interaksi antar user atau pengguna dengan sistem yang dirancang.

2) Activity Diagram

a) Activity Diagram Mengelola Booking Paket Wisata

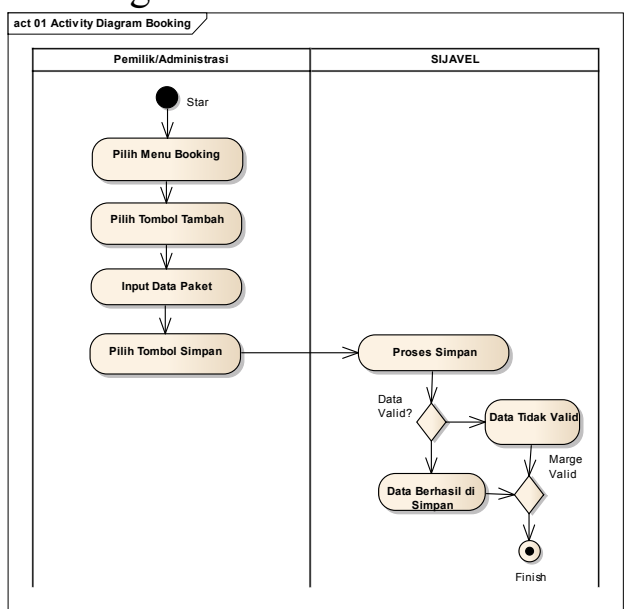

Sumber :(Buani \& Suryani, 2020)

Gambar 2. Activity Diagram

Mengelola Booking Paket Wisata

b) Acvtiviy Diagram Mengelola Data Transaksi

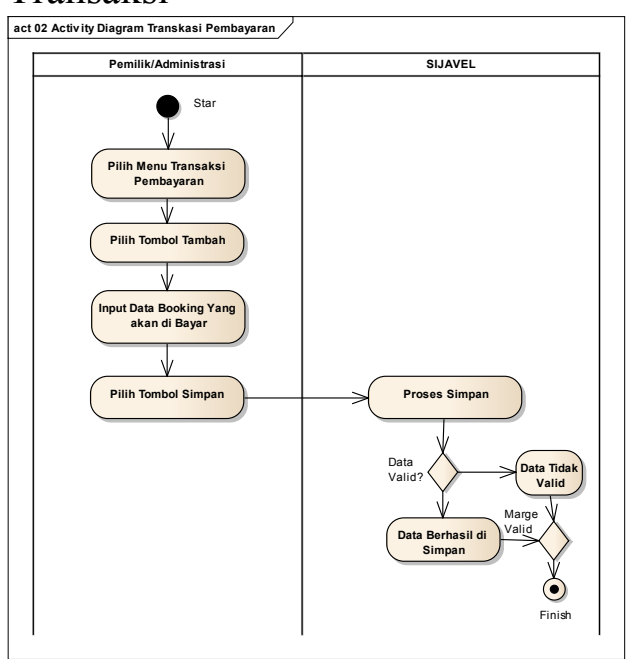

Sumber: (Buani \& Suryani, 2020) Gambar 3. Acvtiviy Diagram Mengelola Data Transaksi 
Gambar 5. Squance Diagram

Mengelola Data Transaksi

3) Squance Diagram

a) Squance Diagram Mengelola Paket Data Wisata

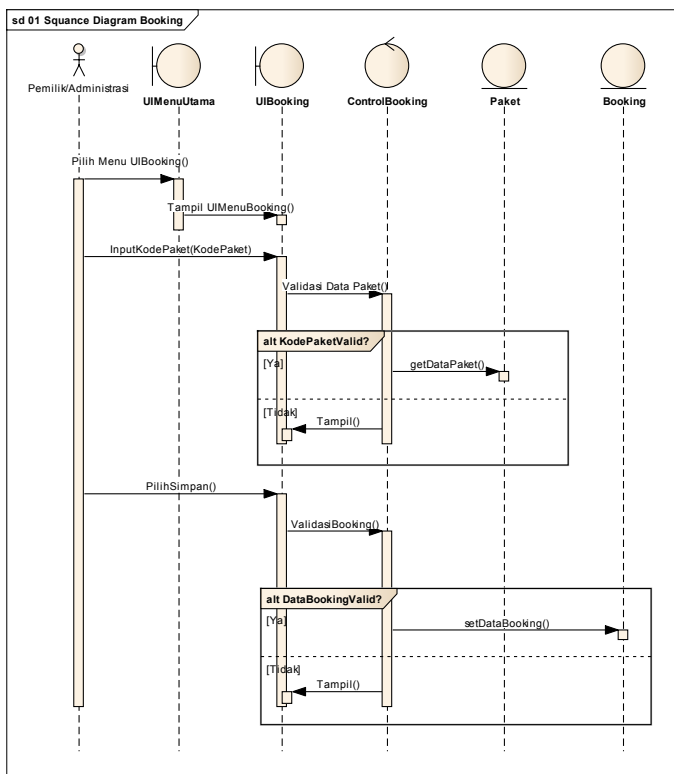

Sumber: (Buani \& Suryani, 2020)

Gambar 4. Squance Diagram

Mengelola Paket Data Wisata

b) Squance Diagram Mengelola Data Transaksi

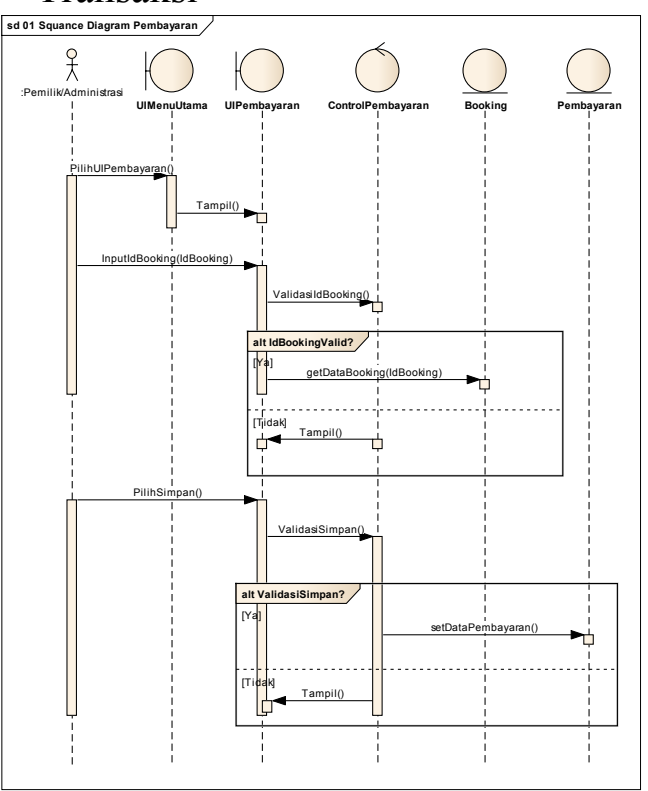

Sumber: (Buani \& Suryani, 2020)
4) Class Diagram

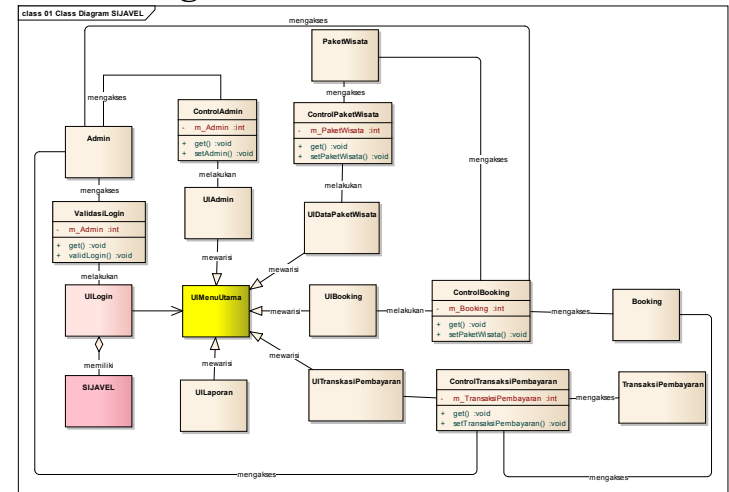

Sumber: (Buani \& Suryani, 2020)

Gambar 6. Class Diagram SIJAVEL

5) Deployment Diagram

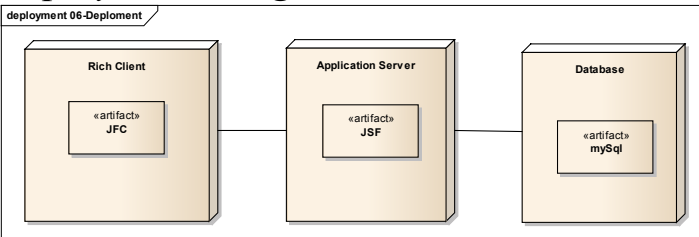

Sumber: (Buani \& Suryani, 2020)

Gambar 7. Deployment Diagram

6) Data Model

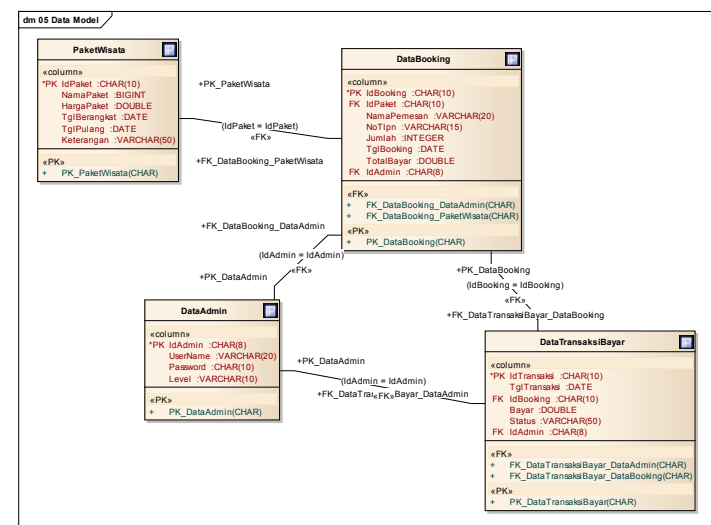

Sumber: (Buani \& Suryani, 2020)

Gambar 8. Data Model

\subsection{Construction (Code \& test)}

Tahapan selanjutnya adalah melakukan implementasi dari disain yang telah di buat menggunakan UML, untuk 
melakukan implementasi database dalam penelitian ini penulis menggunakan database ODBC My SQL, dan untuk implementasi program menggunakan bahasa pemrograman java dan tools yang digunakan adalah NetBean.

1) Tampilan Form Booking

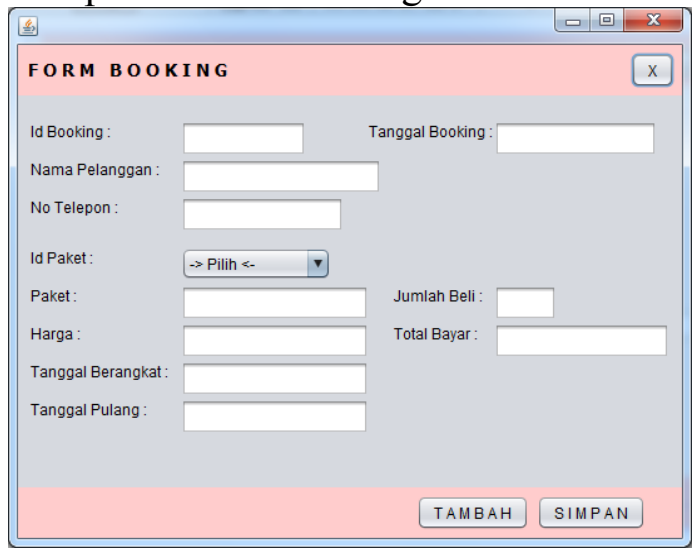

Sumber: (Buani \& Suryani, 2020)

Gambar 9. Form Data Booking

2) Tampilan Form Transkasi Pembayaran

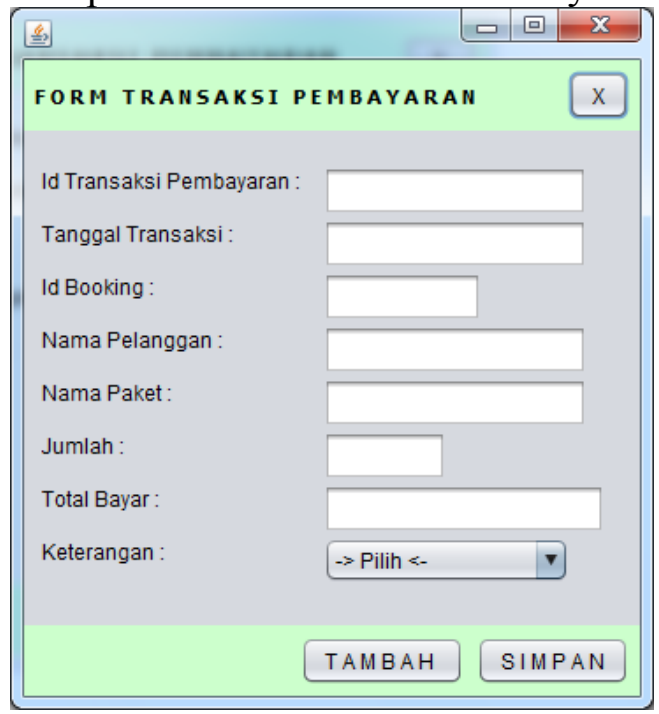

Sumber : (Buani \& Suryani, 2020)

Gambar 10. Form Transaksi

Pembayaran

\subsection{Kesimpulan}

Sistem Informasi Jasa Travel dapat mengatasi semua permasalahan yang terjadi pada Remember Travel, seperti kegiatan administrasi lebih efektif dan efesien, adanya back up data sehingga ketika tejadi kehilangan dokumen masih ada back up. Kelemahan dari SIJAVEL adalah SIJAVEL merupakan aplikasi dekstop yang digunakan untuk pencatatan transaksi booking paket wisata yang dilakukan oleh admin Remember Travel.

\subsection{Ucapan Terima Kasih}

Alhamdulillah puji syukur kami ucapkan kepada ALLOH SWT yang telah meridhoi kami dalam menyelesaikan Penelitian ini. Tak lupa juga kami ucapkan terima kasih kepada Owner dari Remember Travel yang telah menyediakan waktunya untuk penelitian ini, dan kami ucapkan terima kasih kepada pihak-pihak yang terlibat dengan penelitian ini, kami harapkan penelitian ini bisa menjadi sebuah rujukan untuk penelitian selanjutnya.

\subsection{Referensi}

Abdulghani, T., Jaelani, L., \& Ikhsan, M. (2017). Pembuatan Sistem Informasi Tour \& Travel Berbasis Website (Study Kasus Marissa Holiday Cianjur). Media Jurnal Informatika, 9(2), 99-108.

Buani, D. C. P., \& Suryani, I. (2020). Laporan Akhir Penelitian Mandiri STMIK Nusa Mandiri Jakarta. Sekolah Tinggi Manajemen Informatika Dan Komputer Nusa Mandiri.

Jayanti, D., \& Iriani, S. (2014). Sistem Informasi Penggajian Pada CV . Blumbang Sejati Pacitan. Speed, 6(3), 36-43.

https://doi.org/10.3112/SPEED.V6I3.1 041

Kamil, H., \& Duhani, A. (2016). Pembangunan Sistem Informasi Pelayanan Jasa Laundry Berbasis Web Dengan Fitur Mobile Pada 21 Laundry Padang. Seminar Nasional Sains Dan Teknologi Fakultas Teknik Universitas Muhammadiyah Jakarta, 1-9. https://media.neliti.com/media/publicat ions/172316-ID-pembangunan-sisteminformasi-pelayanan-j.pdf

Maulana, G. G., \& Rispiandi. (2015). 
Sistem Informasi Pelayanan Jasa Tour dan Travel Berbasis Website Electronic Commerce ( Studi Kasus Ninetours Indonesia ) *. Sistem Informasi, 3(1), 49-60.

Pressman, R. . (2015). Rekayasa Perangkat Lunak: Pendekatan Praktisi Buku I (Andi).

Ridlowi, R., \& Himam, F. (2018). Inovasi pada Organisasi Pemerintah: Tahapan dan Dinamika. Gadjah Mada Journal of Psychology (GamaJoP), 2(1), 22. https://doi.org/10.22146/gamajop.3186 6

Riskiono, S. D. (2018). Sistem Informasi Pelayanan Jasa Tour Dan Travel Berbasis Web (Studi Kasus Smart Tour). Jurnal Informasi Dan Komputer, 6(2), 51-62. https://doi.org/10.35959/jik.v6i2.112

Rusmayanti, A. (2015). Sistem Informasi Pengelolaan Keuangan Pada Desa Ngadirejan. Speed - Sentra Penelitian Engineering Dan Edukasi, 6(2), 35-39. http://www.ijns.org/journal/index.php/ speed/article/view/1321/1309

Susanto, W. E., \& Astuti, Y. G. A. (2017).
Perancangan E-Learning Berbasis Web Pada SMP Negeri 3 Patuk Gunungkidul Yogyakarta. Bianglala Informatika, 5(2). 